Alejandro Vázquez $A$.

\title{
Los Poemas de la Maternidad
}

\section{VISION}

N las grandes ciudades. hay siempre coches miserables a la puerta de las maternidades.

Nadie sabe de dónde vienen con sus cargas misteriosas, eternizados, esperando, semejan brujas licenciosas.

Los vientres curvos, convulsos de energía de siglos. esfuches del deseo hecho vida ofrecen su martirio.

Estas madres humildes de la miseria y el pecado caminan agobiadas. 
ocultando bajo el manto

las lágrimas de algún amor desconsolado.

¡Pobres mujeres que no saben

si llevan palpitando en sus entrañas

a un asesino o a un artista!

¡Barcas negras sin destino, ricas de un oro misterioso!

El amor que bendijo sus vientres - nube de espasmos inmortalesse sublimiza en lo inconsciente hasta el dolor de hacerlas madres.

Yo las he visto sobre los lechos propicios de las maternidades, en el momento único, transfiguradas, bellas como símbolos, dolientes y temblorosas, hiriendo al aire con sus gritos,

canto del misterio eterno que es un jirón de infinito!

$\mathrm{Y}$ he discurrido entre los lechos ásperos de las novicias trémulas, que aguardan la hora de la tortura misteriosa avergonzadas, como colegialas.

Náufragas en la sala sórdida, entre mujeres indiferentes, sin ternura, cuya alma es como un fórceps, las primerizas desnudas son como un nudo de angustias! 
¡Oh! yo hubiera querido tener entre mis manos, para dejarla entre ellas, mi doliente ternura, porque mi voz temblaba de temor y de pena, entre sus rostros envejecidos, espesados de dudas.

Luego he pasado por entre las que tienen al lado a su recién nacido, cuyas miradas húmedas, están oblícuas de tanto mirarlo como a un tesoro aparecido.

Por entre las que ya han olvidado el fragoroso recuerdo para gastar sus voces débiles en canciones de cuna para el tierno capullito de rosa de su ensueño.

IAh, sin descanso, madres, vigilad el retoño que duerme, tened la mano junto al corazoncito enloquecido, no vaya a ser que el sueño se eternice; no se vaya a quedar para siempre dormido!

\section{EL RECIEN NACIDO}

Tengo en mis manos al recién nacido. ino pesaría más un puñado de rosas!

Sus manitos de seda que no han tocado nada, limpias del bien y del mal, arañan el aire, desorientadas. 
1Oh, qué hermoso parece y qué emoción me infiltra, profunda y nueva, como un llanto, desconcertante, como la muerte!

¡Tengo en mis manos al recién nacido. frágil como un botón amanecido!

Sangre nueva que tiembla ingenua y pura como una estrella: este pequeño ser. es para mi el misterio absoluto, embrión de drama, promesa y fruto que ha de gozar y padecer.

Escucho su llanto, que es como un canto de pájaro. y me parece alegre y fresco como la voz de un surtidor, que después de un eterno silencio hubiera llegado a nosotros envuelto en un rayo de sol. Llanto que es himno de ternura desconocido y profundo. esperado y presentido como desde el infinito.

IOh, la emoción bendita del primer llanto del recién nacido! 
Lo tengo entre mis manos

y es tan suave y liviano.

que me da miedo acariciarlo

como a un capullo, por no deshojarlo!

¡Con qué placer seguiría yo el curso de esta vida iniciada hace un momento. de esta anómina fuente de amor no salpicada aún por los venenos de la miseria y la desolación!

Siento nacer en mi una potente ansia de protección para esta suave almita que nació desamparada: y pienso en la emoción que tendré un día. cuando entre mis manos temblorosas, como a un Dios diminuto y sonrosado, de un hijo mío, levante el cuerpecito perfumado!

¡Entre mis brazos, el recién nacido, muy suavemente, se quedó dormido!

ALEJANDRO VAZQUEZ A. Maternidad del Hospital de San Borja, 1919. 